EDW psychological research. New York: Holt Rinehart \& Winston, 1960.

HARMAN, H. Modern factor analysis. Chicago: University of Chicago Press. 1960 .

KAISER. H. F. The varimax criterion for analytic rotation in factor analysis. Psychometrika, 1958, 23, 187-200.

LACEY,J. I Somatic response patterning and stress: Some revisions of activation theory. In M. H. Appley and R. Trumbul (Eds.), Psychological stress: Issues in

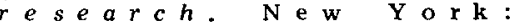
Appleton-Century-Crofts, 1967.
OPTON, E.. JR., RANKIN, N. O., \& LAZARUS, R. S. A simplified method of heart rate measurement. Psychophysiology, 1966, 2, 87-97.

OSGOOD C. E., SUCI G. J., \& TAN NENBAUM, $\mathrm{p}$. H. The measurement of meaning. Urbana, Ill: University of Illinois Press, 1957.

SLANKIS, I. V. The relations between verbal judgements of pleasingness and choice behavior, and between verbal judgements of interestingness and exploration time. Unpublished MA thesis, University of Toronto, 1965.

\section{Human operant eyelid conditioning: Auditory vs visual reinforcing signal*}

\author{
DONALD A. SCHUMSKY, JOHN TRINDER $\dagger$, and CHARLES L. RICHMAN $\dagger \dagger$ \\ University of Cincinnati, Cincinnati, Ohio 45221
}

The human eyeblink response was conditioned as a free operant, employing a double-blind yoked-control procedure. High levels of conditioning were obtained with experimental Ss by employing either a visual or auditory reward signal. No significant differences in response level were associated with reward signal modality in conditioning nor, as previously hypothesized, for yoked controls. Evidence for a significant conditioning effect was obtained even when the data of only "unaware" Ss were considered.

In a previous paper (Schumsky, Richman, \& Trinder, 1967), a method was presented for conditioning the eyeblink response as a free operant, employing a double-blind yoked-control procedure. The results of that experiment yielded a high level of conditioning with experimental Ss. In addition, yoked-control Ss showed a marked tendency to reduce the number of eyeblinks through the conditioning period, with an observed return to previous operant levels during the extinction period. Two potential explanations of this latter

* The final draft of this paper was prepared while the senior author was a Special Postdoctoral Fellow at the Center for Research in Human Lear.:ing, University of Minnesota. Partial support was provided by grants to the Center from ise National Science Foundation (GB-17590), the National Institute of Child Health and Human Development (HD-01136 and HD-00098), and the Graduate School of the University of Minnesota.

+Now at the Department of Psychiatry College of Medicine, University of Cincinnati, and Veterans Administration Hospital, Cincinnati, Ohio.

+Now at Wake Forest University, Winston-Salem, N.C. 27106 finding were offered. The first was a conditioning explanation. The second involved the suggestion that employing a visual signal as reinforcer led to less blinking in order to "maintain unhampered vigilance." The present experiment was intended as a replication and extension of the previous one (Schumsky et al, 1967). As before, Ss were run in pairs in the double-blind yoked-control procedure. In order to evaluate whether or not the visual signal per se produced the reduction in eyeblinks noted with previous yoked-control Ss, an auditory or a visual signal was used as reinforcing signal.

Another consideration from the previous paper involved the role of the S's verbal reports of "awareness," as conditioning. The research indicated much higher levels of conditioning for "aware" Ss. Nevertheless, a significant conditioning effect was also obtained for the "nonaware" Ss. The data on which such awareness judgments were made involved a simple question: asking Ss if they knew "what was happening." In view of the they related to their level of implications of such awareness data upon views which require $\mathrm{S}$ awareness for conditioning to take place ( $\mathrm{cf}$. Spielberger, 1962), the present study reconsidered the issue, employing a questionnaire like that previously used by Spielberger \& Levine (1962) in the verbal conditioning context.

\section{METHOD}

The Ss in this experiment were 96 male undergraduate introductory psychology students who were participating in the experiment in order to fulfill a course requirement.

The general procedure employed was essentially like that in the previous Schumsky et al experiment. Ss were run in pairs, each pair including a conditioning $\mathbf{S}$ and his yoked control. The Ss were told that they were in a competition for points and that the experimental problem was for them to figure out what it was they had to do to earn a point. The two Es counting S's eyeblinks had no preexperimental knowledge as to which $S$ was the conditioning $S$, thus effecting the double-blind aspect of the experiment. Reinforcements (points) were administered to both $\mathrm{Ss}$ when the experimental $\mathbf{S}$ blinked his eye. The nature of this reinforcement constituted the major independent variable of the experiment. All Ss throughout the experimental session wore a set of earphones. They were told that when they earned a point they would either hear a tone through the earphones or see a light flash to signify the earning of a point. Randomly, half of the experimental pairs were administered either light or tone reinforcement.

A one-way-vision screen was used to prevent $S$ from seeing $E$ throughout the course of the conditioning phase of the experiment. In the previous experiment, $S$ could see the $\mathrm{E}$ who was counting his eyelid responses, although he was unable to see either the $\mathrm{E}$ administering reinforcement or the yoked $S$ and his respective $E$. Experimental instructions were administered on a face-to-face basis by one $\mathrm{E}$ (the senior author). The Ss were informed that they were in front of a one-way-vision screen and that there was an E counting (true) and signaling earned points (not true) for each of them. Postexperimental interviews were conducted on a face-to-face basis with each $S$ interviewed by his own paired E-counter. A partition prevented Ss from seeing each other. Partitions on the $E$ side of the apparatus also prevented Es from seeing each other. The Es counting responses could see one $\mathrm{S}$ only. The $\mathrm{E}$ administering reinforcement could see both Ss.

In addition to the instruction period and the postexperimental interview, 
the part of the experiment concerned with conditioning the eyeblink was divided in to three main periods, lasting a total of $4 \mathrm{~min}$. There was an initial 1-min period for determination of operant level, followed continuously by a 2-min conditioning period and then a 1-min extinction period. Eyelid responses were counted and recorded for each $15 \mathrm{sec}$ throughout this part of the experiment.

\section{RESULTS}

The major results of the experiment are summarized in Fig. 1, which presents the mean number of eyeblinks per 15 -sec period throughout the experiment. $S$ groups are defined by the nature of the reinforcing signal they received and whether they were conditioning or yoked-control Ss. Separate statistical analyses were performed on data from each of the three experimental periods: operant, acquisition, and extinction.

There were no significant differences among groups during the operant period, despite what appears in Fig. 1 to be a considerable difference in mean level of response. As expected, the hypothesis of a common preconditioning origin was not rejectable.

The acquisition phase of the experiment was analyzed by means of a two-between (modality and experimental vs yoked) and one-within (the eight $15-\mathrm{sec}$ periods of the conditioning phase) analysis of variance. Significant effects were associated with trials $(F=2.27$, $\mathrm{d} f=7 / 644, \mathrm{p}<.05$ ), the experimental vs yoked control designation $(\mathrm{F}=26.30, \mathrm{df}=1 / 92, \mathrm{p}<.01)$, and the interaction of these two factors $(F=5.05, \quad d f=7 / 644, \quad p<.01)$. Figure 1 provides visual evidence of the success of the conditioning procedure. No significant effects were associated with the modality of the reinforcer, either as a main effect or in interaction with the other variables.

Analysis of the data from the extinction phase of the experiment was generally in support of the acquisition analysis. Significant trials $(F=8.73, \quad$ df $=3 / 276, \quad p<.01)$ and Experimental vs Yoked by Trials interaction $(F=46.3, \quad \mathrm{df}=3 / 276$, $p<.01)$ effects were obtained during extinction. These latter trend differences are evident in Fig. 1. No other mean square in the analysis of extinction data approached significance.

A separate analysis of the acquisition period data of yoked-control Ss was carried out to provide a more sensitive examination of the effects of modality of reinforcer upon these Ss. It was a possibility that effects upon these groups were masked

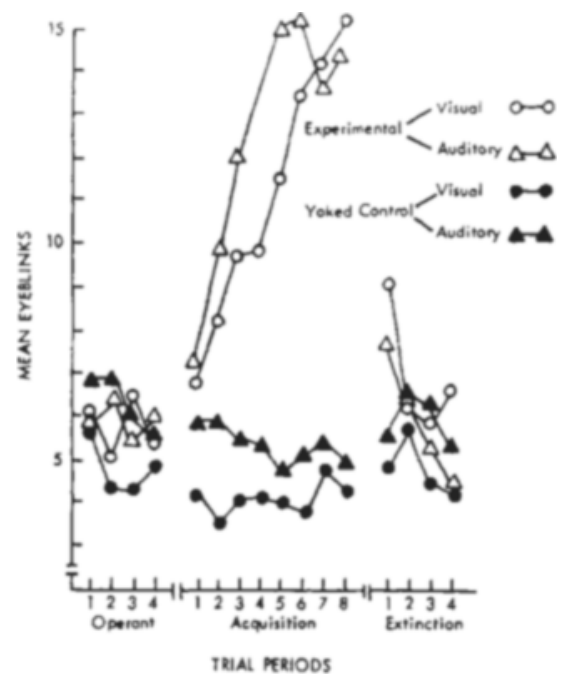

Fig. 1. Mean number of eyeblinks for all experimental groups in each $15-\sec$ trial period.

by averaging in the overall analysis. Thus, two-way analysis of variance was performed to evaluate the effects of modality across trials for yoked-control Ss only. No significant effects were obtained. The differences discernible in Fig. 1 are apparently not statistically significant. The results of the present experiment do not support the notion that the decline in eyelid responding for yoked-control $S s$ in the previous experimenent was due to the use of a visual signal for reinforcement. Direct evidence in support of a conditioning account of this response reduction would seem harder to obtain. Noteworthy in this regard is the yoked-control $\mathrm{S}$ who was observed to hold his eyelids open with his fingertips during the conditioning phase of the experiment. Upon later postexperimental questioning, he reported the observation that he received points when he did not blink his eyes. Thus, he held them open.

The failure to obtain a significant decline of responding across trials for yoked control Ss in the analysis of variance of the acquisition period was perplexing. The variability of responding of yoked control Ss during this period in the present experiment was much greater than in the previous experiment. Yet, when comparison was made between the operant period and the last four 15 -sec periods of acquisition, a significant overall decline was observed $(t=1.83$, $\mathrm{df}=47, \mathrm{p}<.05$ ). A small downward trend can be observed for these groups in Fig. 1, although this effect is much reduced when compared to the previous study.

An S was judged "aware" if he was able to verbalize the relationship between blinking his eyes and the administration of a rewarding signal. About half of the experimental (11 auditory and 14 visual) and $85 \%$ of the yoked control Ss ( 22 auditory and 19 visual) failed to verbalize this relationship. Employing the data of the 25 unaware conditioning Ss only, comparisons were made between the mean for the operant period and the mean of the last four conditioning periods. As in the previous study, a significant increase in mean eyeblink was found with data from unaware conditioning Ss $(t=2.70, d f=24$, $\mathrm{p}<.01$ )

The results of the present study are in agreement with those of the original Schumsky et al (1967) study, demonstrating the free operant conditioning of the eyeblink response employing a double-blind yoked-control procedure. The use of an auditory vs a visual signal as reinforcer in the present study led to no differences. Thus, no support was offered for the explanation of declining rate of eyeblink for yoked Ss due to attention to a visual signal. It would appear that the alternative explanation of some sort of conditioned rate decrease is probable. Such explanations have been offered for similar decreases in other situations (cf. Kimmel, 1967). Yet, much less decline and generally more variable performance was noted for yoked Ss in the present study when compared to the previous study. This may have been due to the change in apparatus employing a one-way-vision screen, which prevented $S$ from seeing the $E$ counting his eyelid responses.

Despite the use of a more careful and objective criterion for deciding between aware and nonaware $\mathrm{Ss}$, a significant conditioning effect was obtained even when the data of nonaware $S s$ were considered alone. The hypothesis of a necessary relationship between the occurrence of conditioning and an S's verbal report of awareness does not seem to be supported by data gathered with the procedures employed here.

\section{REFERENCES}

KIMMEL, H. D. Instrumental conditioning of autonomically mediated behavior. Psychological Bulletin, 1967, 67, 337.

SCHUMSKY, D. A, RICHMAN, C. L., \& TRINDER, J. Free operant conditioning of the human eyelid response. Psychonomic Science, 1967, 8, 237-238.

SPIELBERGER, C. D. The role of awareness in verbal conditioning. In $C$. $W$. Erikson (Ed.), Behavior and awareness. Durham, N.C: Duke Unjversity Press, 1962.

SPIELBERGER, C. D. \& LEVINE, $S$. $M$ What is learned in verbal conditioning? Journal of Verbal Learning \& Verbal Behaviox, 1962, 1 125-132. 